\title{
Suggestions on Countermeasures for Promotion of Bidirectional Integration of Urban Development and Network Subculture in Ningbo City

\author{
Yunfeng Ge
}

Ningbo Dahongying University, Ningbo, 315175, China

Keywords: urban development; network subculture; integration

\begin{abstract}
The development of network subculture conforms to the connotation of urban development. Communication and development of network subculture mitigate social contradictions. Urban development is served as a sort of excitation and molding for network subculture. For bidirectional integration of urban development and network subculture in Ningbo City, the government should establish a network subculture risk pre-warning mechanism, enhance the education of network information literacy, take the lead in finishing network real name system through the establishment of individual credibility system, and provide various guarantee measures.
\end{abstract}

\section{Introduction}

As a city specifically designed in the state plan, a coastal open city and an economic center of the southern wing of Yangtze River Delta in China, Ningbo City is of strong industrial base, developed private economy and obvious system and mechanism advantages. Besides, urban development of Ningbo is also in the stage of functional promotion, multi-set development and construction of a networked metropolis. Large investment, big integration and great integration also provide precious opportunities to the development of urban complex. By September, 2012, the number of online users in the city is approximately 5,960,000 (including 4,840,000 fixed network broadband netizens and 4,850,000 mobile phone netizens). Calculated by the total number of new and old persons in Ningbo as $10,062,400$ by the end of 2011 , the Internet penetration is about $59.2 \%$ in our city, approximately $20 \%$ higher than the national average, and almost $3.1 \&$ higher than the average level of Zhejiang Province. The information flow rate reaches 200G per second. In the course of urban development, expansion of urban geographic space, variation mode of organization structure, information circulation channel and information interpretation mode rely on the relations with network subculture. It is impossible to really understand urban development without network subculture. Likewise, open architecture represented by urban development also provides a variety of probabilities for renewal of network subculture. Therefore, it is of bidirectional integration relationship between urban development and network subculture.

\section{Related Concepts of Urban Development and Network Subculture}

Urban development is served as comprehensive deployment of urban future planning, reasonable layout of the city and integrated arrangement of various construction projects as well as the basis for urban construction and management. To properly construct a city, we must forecast and reasonably specify urban development orientation, scale and layout, make proper environmental forecasting and evaluation, coordinate relations of various aspects in the development, and make overall arrangements for various construction projects, making construction and development of the whole city to reach general effects of advanced technology, reasonable economy, cooperative "flesh and bone" and beautiful environment, and creating favorable conditions for dwelling, working, learning, communication, rest and various social activities of urban residents.

Network subculture is relative to network mainstream culture. Marginal culture in network virtual space is a kind of special system of cultural value, thinking model and mode of life gradually 
formed, worshiped and promoted by netizens in network. Actually, network subculture is a sort of people-oriented cultural inclination as well as a sort of rational recovery of mass culture.

\section{Current Situation Analysis on urban Development and Network Subculture}

\section{(I) Conformity of network subculture development to connotation of urban development}

1、Open network subculture accords with reform spirit of urban development

Due to virtuality, anonymity, openness and freedom of network, a network world is formed, which is characterized with high openness, high freedom, high equality and high decentralization of authority. Therefore, the base for network subculture is open. Practice has proved that reform is strong motivation of urban development as well as progress and self-improvement of urban development. A city excluded from reform or development will come to a halt. Reform is served as continuous source power of urban development. In this sense, the base for network subculture complies with reform spirit of urban development.

2、Shared network subculture is consistent with the spirit of inclusiveness of urban development

With the development of network, people are willing to share, communicate and share information on the Internet. Wide transmission of network subculture in the society mainly depends on the core of network subculture: sharing. Just because of such spirit of sharing, it also results in rapid transmission and prosperity of network subculture. For better development of a city, the spirit of inclusiveness is undoubtedly of great importance. Regional inclusiveness, cultural inclusiveness, harmonious coexistence between external population and local population and treatment of vulnerable groups in urban development indicate that the spirit of inclusiveness is served as driving force for sustainable development of a city. Therefore, sharing of network subculture is consistent with the spirit of inclusiveness of urban development.

3、 Concentrated network subculture is consistent with the characteristic development road in urban development

Network subculture has its evolution process, with social reflection and progress left and waste matters removed. Therefore, the value of network subculture lies on its concentration instead of communication. The key of urban development is not the height of high buildings and large mansions or the value of GDP. Instead, it is sustainable development left after long-term development, namely features of urban development. That is the source for vitality of urban development. For instance, the development of its primate economy must be mentioned when urban development of Zhejiang Province is mentioned. That is the feature of urban development. The value of network subculture lies on concentration, which is consistent with the characteristic development road in urban development.

(II) Communication and development of network subculture mitigate social contradictions, which is served as reducing valve for social management. At the same time, it promotes further optimization of social function.

Actually, network subculture is a sort of people-oriented cultural inclination as well as a sort of rational recovery of mass culture. In the course of urban development, social contradictions in various aspects are intensified. Individual needs are satisfied through self expression via network buzzwords. Network provides vast netizens with a platform for self-expression through network spoof, tradition deconstruction, extending individuality and social sarcasm, allowing netizens to give vent to abnormal emotions. However, what brought by mass relief is social progress instead of social retrogress. To some extent, the development of network subculture mitigates social contradictions. Public groups are engaged in the discussion on their topics. As a result, spiritual emptiness can be remitted, and the sense of belonging can be obtained, so as to avoid conflicts in realistic society. Certainly, social development will become a process of self-improvement, if their cultures are respected and adopted.

Network subculture plays a positive role in relieving pressure and remitting public emotions. Moreover, it is served as a reducing valve for social management. Through expression, netizens let the government to understand national conditions and popular wills, promoting civil servants to 
improve works, and supervising and urging just solutions to relevant issues. To some extent, network netizens' opinions reflect interest demands of different groups. At the same time, various queries and issues can be reflected to ruling center of the society through this window, providing important basis for value acceptance or rejection of public policies and weighing the advantages and disadvantages.

(III) Urban development is a sort of excitation and molding for network subculture.

1、Urban development is served as carrier of network subculture.

Culture is soul and spirit of a city. Each city has its unique history and culture, distinct personality and expression symbols as well as complete atmosphere and spiritual qualities. Urban development influences and decides way of thinking, way of act and mode of life of citizens in a city. Network subculture is a kind of mass culture. In this sense, urban development is served as breeding and development soil and environment for network subculture. Urban development provides network subculture with space, capital and environment. Urban development is served as carrier of network subculture.

2、 Network subculture is served as "binding agent” for resultant force of urban function.

Just like a bonding factor, network subculture gathers together people with common values or common interests. They have common topics worthy of deep research. Independent development of network subculture maintains common interests, and enriches and develops mainstream culture at the same time, thus making it convenient to form identity of social structure or social relations. In the transformation process of a city to development pattern with knowledge economy as the core, network subculture plays a decisive role. The level of network subculture in a city has a direct effect on its innovation ability and molding of innovation atmosphere. At the same time, the development of network subculture in a city already gradually surpasses narrow cultural fields, and permeates toward industry, infrastructure, society, urban rehabilitation and even overall orientation of city. The degree of cultural association is greatly expanded, and it gradually becomes "binding agent" for resultant force of urban function.

\section{Suggestions on Countermeasures for Promotion of Bidirectional Integration of Urban Development and Network Subculture in Ningbo City}

(I) The government should establish a network subculture risk pre-warning mechanism, and grasp the principal line of "the people's livelihood in Ningbo City" in the course of urban development, so as to realize risk control over network subculture.

Ningbo City belongs to the east Zhejiang. Represented by the east Zhejiang school, Zhejiang culture is an integral part of excellent traditional culture of China. At the same time, Zhejiang culture also embodies distinct regional characteristics of Zhejiang, which is served as "cultural gene" deeply seared on bodies of Zhejiang people. In the formation process of Internet public opinions, such "cultural gene" constitutes Internet culture unique to Ningbo, and condensates into Ningbo spirits of "constantly strive to become stronger, stubborn and unyielding, lay great emphasis on commerce and less emphasis on politics, and pursue for substantial results". Such style of ignorance to virtual work and pursuit for actual gains decides the fact that the government should establish a risk pre-warning mechanism for network subculture. No matter whether it is information related to politics, it will certainly arouse the public's attention as long as it is correlated with the people's livelihood. Moreover, distinct and rapid answer is in real need of public opinions.

As a city with developed economy and good network infrastructure, Ningbo gets rapid development in the Internet public opinions. Therefore, relevant risks will go up accordingly while netizens issue information and communicate opinions. For the government, the main control measure is to establish a risk control system centered on laws and regulations. Moreover, technical, economic, educational and other means should be used for comprehensive and proper control over social issues in cyber space. At the same time, the government should inject media literacy education into the development of information technology, and directly lower down bad information communication risk from the perspective of citizens. With respect to supervision, 
multidirectional transmission of information may politically cause the increased risk of public opinion. Economically, online transaction is active in Ningbo. Once information security is threatened, huge financial loss will be caused, and many public interests are related. In terms of spiritual civilization construction, network users in Ningbo are already not "three highs" crowds restricted to the original hypothesis. Local network culture in Ningbo involves various social brackets, and integrates into new diversified network culture. To formulate a complete control system from the perspective of risk control is served as an important strategic step for future network development of Ningbo.

(II)The government should enhance the education of network information literacy, and lead ordered and healthy development of network subculture with tolerant posture and development insight.

The government should treat network subculture with tolerant posture and development insight. If the government treats network subculture with the modes of "prohibition and blocking", it will be just the opposite of what the government wishes. At present, the government fails to play an enough role in the network. The reason for spreading of rumors is that the government fails to tell the truth without delay. In the network society, political parties and the government are not unique owners of information authority in the network society any more. Leading authority of traditional government information is continuously reduced. The government authority is also under continuous challenges. Moreover, some local governments are relatively weak in democratic governing capacity, not strong response competence and incomplete news spokesman system. Under the guidance of wrong concept of political achievements, some local governments, for so-called local government images, always lose authority status of public opinions during the occurrence of critical incidents. Consequently, the status of government as information power corpus is weakened. Retreat of government information authority and expansion of netizens' authority make it easy for public opinions to evolve into government crisis.

During the outbreak of government public crisis, all works for crisis settlement will become passive if the government only makes response instead of resetting topics for discussion. The only method to change such passiveness into initiative is to positively fight for rights of speech of public opinions and reset topics for discussion. Decay laws of Internet public opinions provide basis for our guidance of Internet public opinions, especially "setting of topics" and "topic management”. On the one hand, the government should master opportunity, rhythm and strength of public opinion guidance according to changes in public opinions. On the other hand, the government should positively set new topics, and transfer the public's attention to topics out of crisis through "hotspot transfer". Moreover, the government can utilize its media resources for all-around report on new topics, promoting rapid formation of expected public opinions. In the management of crisis public relations and topics, the government should not solve all issues with one strategy. Instead, the government must take diversified measures to gradually transfer the public' attention, and lower down the public's attention interests in crisis.

(III)The government should establish individual credibility system, and implement network real name system.

For such a city with distinct mercantilism tradition like Ningbo, network life of netizens in Ningbo is of transactions to a large extent. The most important thing of commodity transaction is "good faith". This happens to have the same view with the essence of network real name system. Government management departments can utilize this integrating point to push out a set of trail individual credit system in Ningbo website, Oriental Hotline and other mainstream websites, encourage websites of Ningbo to form honest and responsible pursuits in network atmosphere of Ningbo by giving higher user rights or practical awards. The network real name system through individual credit system can be accepted by both the government and citizens. Ningbo has unique regional culture: mercantile, realistic, steady and conservative. In the perfection process of national legal institution, the progressive real-name individual network credit system maybe is a good attempt for Ningbo with respect to the way of mastering network culture management according to local conditions. Specifically, the government can establish an individual credit registration system 
and a risk prevention system, and take disciplinary measures for actions against honesty and credibility.

\section{Acknowledgments}

This paper is a planning subject of philosophy and social science in Ningbo City in 2011: Research on Bidirectional Integration of Urban Development and Network Subculture (subject No.: G11-C09).

\section{References}

(1) Deng Jing and Meng Qingmin, Review for New Urban Development Theory, Urban Development Studies, 2001 (01);

(2)http://www.chinacity.org.cn/ China city development net

(3)Research Report on Network Culture Development in Ningbo City

(4) Zhou Min and Yang Fuchun, New Media Environment and Network Youth Subculture Phenomenon, Journalism Lover, 2011 (09);

(5)Meng Dengying, Analysis on Formation of Subculture Concept, Foreign Literature, 2008

6) Ma Zhonghong, Theoretical Orientation of Western Post-subculture Research, Social Sciences Abroad, 2010 (01) 